\title{
Autoantibodies against the specific epitope of human tropomyosin(s) detected by a peptide based enzyme immunoassay in sera of patients with ulcerative colitis show antibody dependent cell mediated cytotoxicity against HLA-DPw9 transfected L cells
}

S Sakamaki, N Takayanagi, N Yoshizaki, S Hayashi, T Takayama, J Kato, K Kogawa, N Yamauchi, N Takemoto, A Nobuoka, T Ayabe, Y Kohgo, Y Niitsu

\begin{abstract}
Background and aims-Recent studies suggest that tropomyosin (TM) may act as a putative autoantigen in ulcerative colitis (UC). Recently, we identified, by computer homology analysis, a specific peptide (HIAEDADRK) in human TM that can bind to HLA-DPw9. The aim of this study was to investigate the presence of autoantibodies against this peptide in UC.

Methods-Antibodies were measured by ELISA with a synthetic peptide in 20 healthy volunteers, 48 patients with UC, 26 with Crohn's disease (CD), eight with primary sclerosing cholangitis (PSC), and six with primary biliary cirrhosis (PBC). The functional significance of antibodies was investigated by antibody dependent cell mediated cytotoxicity (ADCC) against DPw9 transfected $L$ cells using a standard ${ }^{51} \mathrm{Cr}$ release assay.

Results-Optical density values (mean (SD)) of sera from patients with UC (1.40 (0.52)) and PSC (1.65 (0.12)) were significantly higher than those from healthy volunteers $(0.32(0.28)) \quad(\mathrm{p}<0.05), \mathrm{CD}(0.50$ $(0.34))(p<0.05)$ and PBC $(0.14(0.09))$ $(p<0.05)$. Values in UC decreased with clinical improvement. The ADCC activity of UC sera correlated well with antibody titre against this synthetic peptide.

Conclusions-Anti-TM antibody was detected in UC sera by a specific peptide based ELISA with high reproducibility. This peptide may be an antigenic epitope of TM involved in the immunopathogenesis of UC and, perhaps, PSC.

(Gut 2000;47:236-241)
\end{abstract}

Keywords: tropomyosin; antibody dependent cell mediated cytotoxicity; HLA-DPw9; ulcerative colitis

Autoimmune phenomena have been implicated in the pathogenesis of ulcerative colitis (UC). ${ }^{1}$ Das et al have previously reported that IgG antibodies bound to the colonic mucosa of patients with UC and showed antibody dependent cell mediated cytotoxicity (ADCC) activity. ${ }^{2}$ They subsequently identified the anti- gen recognised by these antibodies to be a protein with a molecular weight of $40 \mathrm{kD}{ }^{3}$

Recently, a $40 \mathrm{kD}$ colonic protein was purified from the colon to homogeneity, partially sequenced after proteolytic digestions, and the amino acid sequences of the two peptides derived; the amino acid sequences showed 93-100\% match with the cytoskeletal tropomyosins (TMs). ${ }^{4}$ TMs are microfilamental proteins present in all eukaryocytic cells with organ specific isoforms. ${ }^{5}$

If these TMs play a role as autoantigens in patients with UC, specific antibodies against TMs might be expected to be present in these patients. In this context, Das et al detected the antibody reacting against porcine TM in UC sera, although the responsible epitope involved in immune recognition and the pathogenetic implication of this antibody have not been clarified. $^{4}$

In our preliminary experiments using an assay system similar to that of Das et al, we confirmed that UC patients had the antibody against porcine TM. ${ }^{6}$ However, the incidence of positivity was lower than that of the previous report, ${ }^{4}$ and the reproducibility of the assay was rather poor, possibly because of the inconsistency of the porcine TM preparations.

In patients with UC in Japan, significant accumulation of HLA-DR2-DPw9 haplotype was noted by serological typing of HLA molecules. We have previously investigated the association of HLA class II molecules with TM peptides, and revealed that the tryptic peptide of TM bound to HLA-DPw9 expressing L cells but not to HLA-DR2 or DQ6 expressing $\mathrm{L}$ cells. On the basis of these findings we searched for a sequence which would bind to the HLA-DPw9 molecule in human skeletal muscle $\alpha-\mathrm{TM}^{7}$ that is, a sequence whose relative placement of hydrophobic amino acid anchors are in positions 2, 3 and 6; we identified the sequence HIAEDADRK.

Abbreviations used in this paper: TM, tropomyosin; UC, ulcerative colitis; CD, Crohn's disease; PSC, primary sclerosing cholangitis; $\mathrm{PBC}$, primary biliary cirrhosis; ADCC, antibody dependent cell mediated cytotoxicity; AA, amino acid; PBS, phosphate buffered saline; ALP, alkaline phosphatase; PBMNC, peripheral blood mononuclear cells; OD, optical density. 
Table 1 Characteristics of the study groups

\begin{tabular}{lccc}
\hline Disease category & $\begin{array}{c}\text { No of patients } \\
\text { (male/female) }\end{array}$ & $\begin{array}{c}\text { Age (median } \\
\text { (range) }(y)\end{array}$ & $\begin{array}{l}\text { Disease activity } \\
\text { (active/inactive) }\end{array}$ \\
\hline Ulcerative colitis & $48(18 / 30)$ & $41(18-70)$ & $28 / 20$ \\
Crohn's disease & $26(19 / 7)$ & $30(16-51)$ & $19 / 7$ \\
Primary biliary cirrhosis & $6(1 / 5)$ & $22(18-26)$ & $2 / 4$ \\
Primary sclerosing cholangitis & $3(2 / 1)$ & $34(25-42)$ & $3 / 0$ \\
Healthy volunteers & $20(10 / 10)$ & $33(25-42)$ & - \\
\hline
\end{tabular}

Human muscle tropomyosin

Peptide No 17

$O$ volvulus tropomyosin

(lgG binding epitope)

Shrimp tropomyosin

( $\lg E$ binding epitope)

Shuffled synthetic peptide
153

161

LKEAKHIAEDADRKYEEVARKLVIIESDLERA HIAEDADRKYEEVAR

QEKEAQLLAEEADRKYDEVARKLAMVEADLE

FLAEEADRKYDEVAR

\section{ADEIRKHDA}

Figure 1 Comparison of the amino acid sequence of synthetic peptide with the equivalent region of other tropomyosins (TMs). Aligned are representative sequences from the human skeletal muscle a-tropomyosin, IgE binding epitope of shrimp TM, peptide No 17 from $p 40$ which Das et al reported, ${ }^{4}$ and the antigenic epitope of $O$ volvulus TM. The peptide with the sequence in the shaded area is the synthesised peptide. There is $66.7 \%$ match in nine amino acids between the synthetic peptide (peptide No 17 from p40), the IgE binding epitope of shrimp TM, and the antigenic epitope of $O$ volvulus TM. Shuffled synthetic peptide was composed of the same nine amino acids as the synthetic peptide in a different order.

In this investigation, we established an ELISA with a high reproducibility for the antibodies against TM using a synthesised peptide with a specific sequence of TM (HIAEDADRK) as the antigen. Elevation of antibody levels demonstrated by this assay was specific for active UC and primary sclerosing cholangitis (PSC) but not for Crohn's disease (CD) or primary biliary cirrhosis (PBC). In addition, we demonstrated that ADCC activity in UC sera, when plotted against levels of antibody against the TM peptide, showed a positive correlation.

\section{Materials and methods}

PATIENTS

Serum samples were obtained from the subjects listed in table 1, and informed consent was obtained from each patient.

Diagnoses of UC, ${ }^{8} \mathrm{CD},{ }^{9} \mathrm{PBC},{ }^{10}$ and $\mathrm{PSC}^{11}$ were made according to established criteria, including clinical symptoms, radiological results, blood examination, endoscopy, and pathological demonstration of either inflamed intestinal mucosa for $\mathrm{UC}$ and $\mathrm{CD}$ or liver tissue for PBC and PSC. Disease activity was assessed in patients with UC by clinical history and endoscopy findings and in patients with CD by Bristol's simple index. ${ }^{12}$ Mucosal inflammation in patients with UC was assessed during colonoscopy according to the criteria of Matts. ${ }^{13}$

Twenty eight UC patients with active disease were treated with steroids and mesalamines (Hoechst Marion Roussel, Inc., Kansas City, Missouri, USA) while 14 inactive UC patients were given mesalamines alone. All patients with $C D$ had small intestinal involvement. Nineteen of the patients with active CD received steroids and/or mesalamines. Seven CD patients with inactive disease were treated with mesalamines alone. Two of six PBC patients showed PBC symptoms, and the other four were asymptomatic; all were taking

ursodeoxycholic acid (Axcan Pharmaceutical US Inc. Minneapolis, Minnesota, USA). All eight PSC patients were symptomatic, having intermittent jaundice and pruritus, but they had no colonic symptoms or histological evidence of UC (table 1).

TM PEPTIDE

In accordance with the report analysing the ligand of the HLA-DP molecule, ${ }^{7}$ the sequence in which hydrophobic anchoring amino acids (AA) are located in positions 2,3 and 6 , was searched for in human skeletal muscle $\alpha$-TM using the ProFound Amino Acid database searching program. ${ }^{14}$ The peptide spanning the sequence of human TM (153-161AA), which has $66.7 \%$ homology with the IgE binding epitope of Shrimp TM (fig 1), ${ }^{15}$ was identified and synthesised in a peptide synthesiser (Excel; Millipore Corp., Milford, Massachusetts, USA). A shuffled peptide ${ }^{16}$ composed of the same nine peptides but in a different order was also synthesised.

ELISA FOR DETECTION OF ANTI-TM PEPTIDE ANTIBODY

Each of the 96 wells of microtitre plates (high binding capacity, flat bottomed microplate; Costar, Cambridge, Massachusetts, USA) was coated at $4^{\circ} \mathrm{C}$ overnight with $100 \mu$ l of the synthetic peptide at a concentration of $3 \mu \mathrm{g} / \mathrm{ml}$ in $50 \mathrm{mM}$ phosphate buffered saline (PBS) $(\mathrm{pH}$ 7.4). The wells were incubated initially with $200 \mu \mathrm{l}$ of a blocking reagent (Super block in TBS, Pierce, Rockford, Illinois, USA) for 30 minutes at room temperature and subsequently with $100 \mu \mathrm{l}$ of patients' or normal subjects' sera ( $\times 100$ diluted with PBS) in triplicate for two hours at $37^{\circ} \mathrm{C}$. As a positive control, serum from a rabbit immunised with the synthetic peptide was added in separate wells in the same plate at dilutions $\times 400$ to $\times 6400$. After washing with $20 \mathrm{mM}$ Tris $\mathrm{HCl}$ containing $0.5 \mathrm{M} \mathrm{NaCl}, 0.05 \%$ Tween 20 , and $0.1 \%$ $\mathrm{NaN}_{3}, \mathrm{pH} 7.5$ (T-TBS), the wells were treated with $100 \mu \mathrm{l}$ of alkaline phosphatase (ALP) conjugated goat antihuman IgG (Dako, Carpinteria, California, USA) or goat antirabbit IgG (Dako) in ELISA buffer $(0.05 \%$ Tween 20 in PBS, pH 7.4), respectively, and incubated for one hour at room temperature. After washing with ELISA buffer, the wells were further incubated for two hours at $37^{\circ} \mathrm{C}$ in $50 \mu \mathrm{l}$ of substrate solution $(1 \mathrm{mg} / \mathrm{ml}$ of P-nitrophenyl phosphate in PBS). The reaction was stopped by adding $50 \mu \mathrm{l}$ of $0.3 \mathrm{M} \mathrm{H}_{2} \mathrm{SO}_{4}$. The colour intensity was measured by an ELISA plate reader (ImmunoMini NJ-2300; Intermed, Japan) with a measuring filter of $405 \mathrm{~nm}$.

The specific immunoreactivity of the immune rabbit serum and UC sera was verified by examining their reactivity against the synthetic peptide before and after preincubation with the synthetic peptide or unrelated shuffled synthetic peptide. ${ }^{16}$

ADCC ASSAY

ADCC of UC sera (TM antibody positive sera from five UC patients, TM antibody negative sera from four UC patients) and normal sera 


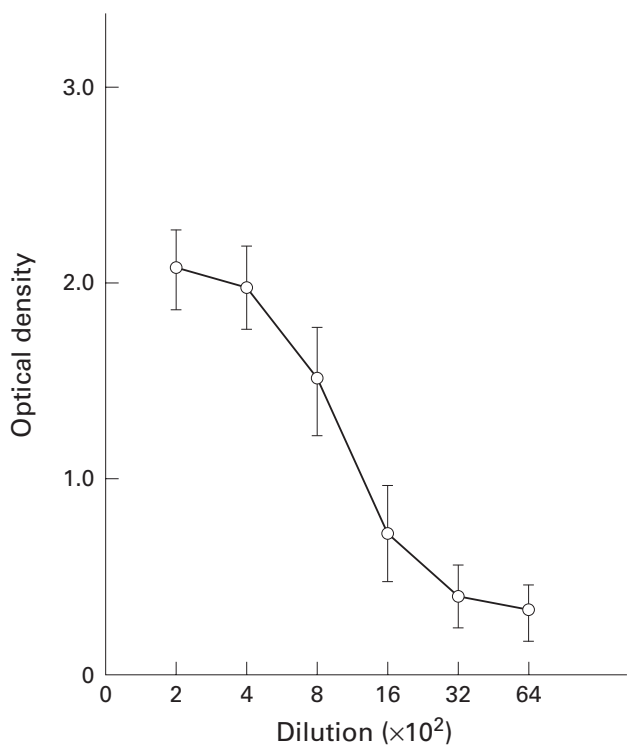

Figure 2 Dilution curve of antibodies in the serum from a rabbit immunised with the synthetic peptide. Specific binding to the synthetic peptide was observed with immune rabbit sera.

(sera from three healthy volunteers) were assessed using the standard four hour ${ }^{51} \mathrm{Cr}$ release assay following the method described previously. ${ }^{17}$ HLA-DPw9 gene transfected $\mathrm{L}$ cells ${ }^{18}$ which were shown to express TM antigens on their surface ${ }^{6}$ were used as targets. Briefly, target cells $\left(1 \times 10^{6} / \mathrm{ml}\right)$ were incubated with synthetic peptide $(3 \mu \mathrm{g} / \mathrm{ml})$ for three hours. After washing with PBS, cells were labelled for two hours at $37^{\circ} \mathrm{C}$ with $100 \mu \mathrm{Ci}$ of $\mathrm{Na}_{2}{ }^{51} \mathrm{CrO}_{4}$ (Daiichi Radioisotope Laboratory, Tokyo, Japan) and washed five times with PBS. Radiolabelled target cells $\left(5 \times 10^{4}\right)$ were incubated with $50 \mu \mathrm{l}$ of UC or healthy volunteer sera at $37^{\circ} \mathrm{C}$ in humidified $5 \% \mathrm{CO}_{2}$ for 60 minutes. The cells were washed three times and resuspended in RPMI 1640 medium. Peripheral blood mononuclear cells (PBMNC) were obtained from healthy volunteers using the standard Ficoll-Isopaque density gradient separation method. Each of the above mentioned target cells was incubated with PBMNC at a final volume of $0.2 \mathrm{ml}$ in each 96 well round bottomed culture plate (Corning 25850, Corning, New York, USA). Thereafter, the plates were centrifuged at $200 \mathrm{~g}$ for five minutes. After four hours of incubation at $37^{\circ} \mathrm{C}, 5 \% \mathrm{CO}_{2}$, the supernatants were collected and radioactivity was measured using a gamma ray counter. Percentage cytotoxicity was calculated as follows: $\%$ cytotoxicity= ((experimental release-spontaneous release)/ (maximum release-spontaneous release) $) \times 100$. Spontaneous release was determined by incubating target cells alone in the medium. Maximum release was obtained by lysing target cells with $1 \%$ Nonidet P-40 (Nakarai Chemical Co., Kyoto, Japan). Values above the mean +2 SD of healthy volunteers were defined as positive.

HLA-DPB1 TYPING

Genotyping of all DPB1 alleles was performed using a polymerase chain reaction-sequence specific oligonucleotide probe (PCR-SSOP)

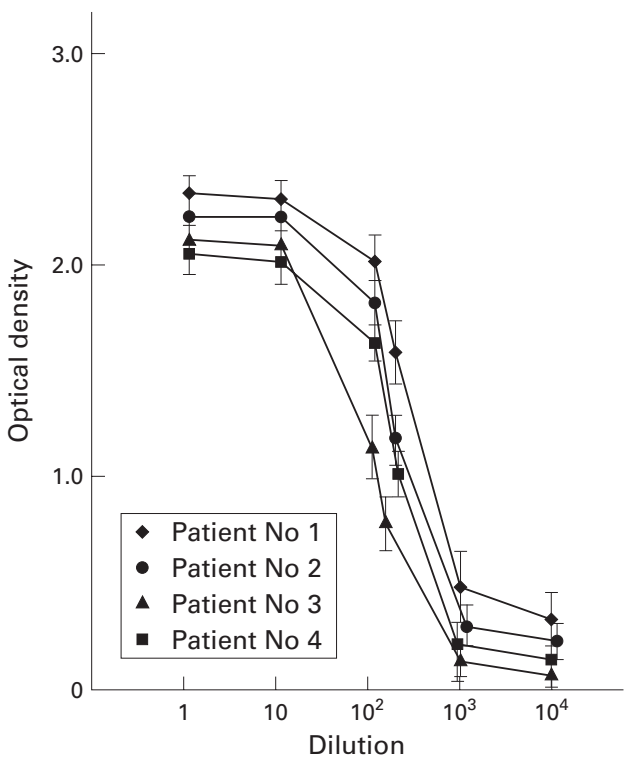

Figure 3 Dilution curves of antibodies in the sera from four patients with active ulcerative colitis. Specific binding to the synthetic peptide was observed in these sera.

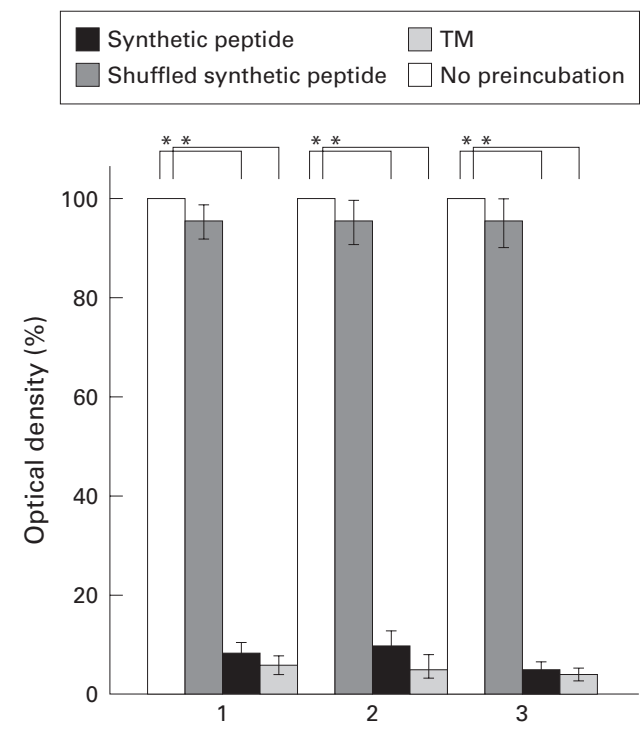

Figure 4 Absorption of antibody with synthetic peptide or tropomyosin (TM). Preincubation with synthetic peptide or TM, but not with shuffled synthetic peptide, decreased reactivities of immune rabbit or ulcerative colitis (UC) sera against TM peptide on ELISA plates. Per cent optical density (OD) values were calculated as follows: \%OD value $=(O D$ value of sera preincubated with synthetic peptide, shuffled synthetic peptide, or TM/OD value of sera without preincubation) $\times 100$. 1, synthetic peptide immune rabbit serum; 2 , serum from UC patient No $1 ; 3$, serum from UC patient No 2.

approach according to the protocols described in the 11 th International Workshop. ${ }^{19}$ Generic primers were used for DPB1 typing; 25 SSOs were used to type 36 DPB1 alleles. Details of the hybridisation conditions have been published previously. ${ }^{20}$

STATISTICAL ANALYSIS

The Mann-Whitney $U$ test was used to assess the standard error of the difference between two means; values were significant if $\mathrm{p}<0.05$. Analysis of variance (ANOVA) parallel line assay was used to determine statistical 


\begin{tabular}{|ll|}
\hline$\circ$ Volunteers without HLA-DPw9 & - CD \\
$\circ$ Volunteers with HLA-DPw9 & \ PBC \\
$\circ$ UC without HLA-DPw9 & - PSC \\
$\circ$ UC with HLA-DPw9 & \\
\hline
\end{tabular}

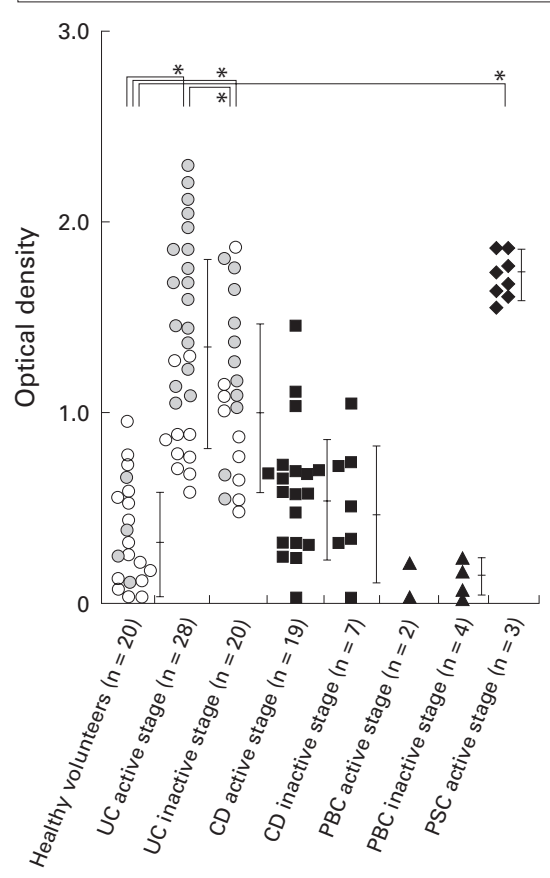

Figure 5 Scattergram of immunoreactivity of each serum sample from 108 subjects against synthetic peptide by ELISA. The immunoreactivity of active ulcerative colitis (UC) sera was significantly higher than that of healthy volunteers $(p<0.05)$, active $(p<0.05)$ and inactive $(p<0.05)$ Crohn's disease $(C D)$, and active $(p<0.05)$ and inactive $(p<0.05)$ primary biliary cirrhosis $(P B C)$. The immunoreactivity of primary sclerosing cholangitis (PSC) sera was also significantly higher than that of healthy volunteers $(p<0.05), C D(p<0.05)$, and PBC $(p<0.05)$. Sera of patients with inactive UC showed less immunoreactivity than that of active UC sera $(p<0.05)$ but much higher immunoreactivity compared with the other groups (v active $C D, p<0.05$; v inactive $C D, p<0.05$; v inactive $P B C, p<0.05$; and $v$ active PSC, $p<0.05)$. Error bars represent mean $(S D)$ in healthy volunteers without $H L A-D P$ w9; in healthy volunteers with HLA-DPw9; in UC patients without HLA-DPw9; in UC patients with $H L A-D P w 9$; in $C D$; in PBC; and in PSC.

significance between values at active and inactive stages. The correlation between ADCC activity and anti-TM peptide antibody titre was evaluated using Spearman's test.

\section{Results}

SPECIFICITY AND REPRODUCIBILITY OF ELISA FOR ANTI-TM PEPTIDE ANTIBODY

A TM peptide with an amino acid sequence conserved in various species was synthesised

Table 2 Levels of IgG antibodies against synthetic tropomyosin peptide in sera from patients with ulcerative colitis, Crohn's disease, primary biliary cirrhosis, primary sclerosing cholangitis, and healthy volunteers

\begin{tabular}{lllr}
\hline Disease & \multicolumn{2}{l}{$\begin{array}{l}\text { Antibodies against synthetic peptide } \\
\text { (active, inactive disease) }\end{array}$} & Positivity $^{a}$ \\
\hline Ulcerative colitis & $1.40(0.52)^{\star} \ddagger$ & $(1.63(0.52), 1.00(0.44) \dagger)^{\star}$ & $68.8 \%$ \\
Crohn's disease & $0.50(0.34)$ & $(0.52(0.34), 0.46(0.37))$ & $15.4 \%$ \\
Primary biliary cirrhosis & $0.14(0.09)$ & & $0.0 \%$ \\
Primary sclerosing cholangitis & $1.61(0.22) \ddagger$ & $100.0 \%$ \\
Healthy volunteers & $0.32(0.28)$ & $5.0 \%$ \\
\hline
\end{tabular}

Values represent optical density (OD) values at $405 \mathrm{~nm}$.

aPositivity: (number of patients whose $\mathrm{OD}$ value is higher than mean $+2 \mathrm{SD}$ of healthy volunteers/number of patients examined) $\times 100$.

${ }^{\star} \mathrm{p}<0.05$ compared with Crohn's disease; $\nmid \mathrm{p}<0.05$ compared with active disease; $\neq \mathrm{p}<0.05$ compared with healthy volunteers. (fig 1). A similar sequence was found in both the IgG binding epitope of $O$ volvulus $\mathrm{TM}^{21}$ and the IgE binding epitope (residues 153161) recognised by sera from patients allergic to shrimp $\mathrm{TM}^{15}$; both sequences had $66.7 \%$ homology with the synthesised peptide sequence. Antibodies developed in the rabbit after immunisation with our synthetic peptide consistently reacted at a serial dilution, as shown in fig 2 . Using a similar assay, sera from four patients with UC were titrated (fig 3). The optical density (OD) values of these sera decreased serially from 10 to $10^{3}$ dilutions. The OD values of serum from the rabbit immunised with the synthetic peptide and two sera from patients with UC (case Nos 1 and 2) decreased when these sera were preincubated with synthetic peptides but did not decrease with the shuffled synthetic peptide (fig 4). Inter- and intra-assay coefficients of variation $(\% \mathrm{CV})$ were small, ranging from 0.9 to 6.4 and from 2.4 to 4.9 , respectively (data not shown).

ANTIBODY LEVELS AGAINST SYNTHETIC PEPTIDE IN SERA FROM PATIENTS WITH UC, CD, PBC, AND PSC

Serum antibodies against the synthetic peptide in patients with UC, CD, PBC, and PSC were assessed by ELISA. The OD values for each patient's serum are shown in the scattergram in fig 5 . As shown in fig 5 and table 2, the mean OD value for sera from UC patients (1.40 (0.52)) was significantly higher than that of healthy volunteers $(0.32(0.28))$. In 33 of 48 patients $(68.8 \%)$ with UC, values were increased above the mean $+2 \mathrm{SD}$ of normal values. There was a significant difference between values for active and inactive UC $(\mathrm{p}<0.05)$. A total of $81.8 \%$ of antibody positive UC patients were shown to have the HLADPw9 genotype (HLA-DPB ${ }^{\star} 0901$ ), which was significantly higher than that in antibody negative UC patients $(13.3 \%)(\mathrm{p}<0.05)$ and healthy volunteers $(20.0 \%)(\mathrm{p}<0.05)$.

The mean OD value of sera from CD patients was not elevated compared with that of healthy volunteers, and only four of 26 patients (15.4\%) showed levels of anti-TM peptide antibodies above the normal value. Each of the eight sera from PSC patients showed values as high as those from active UC patients, while values of PBC patients were all within the normal range (fig 5). Twelve patients with UC who showed high levels of serum antibody at active stage were followed until remission (fig 6), and the group as a whole showed a statistically significant decrease in $\mathrm{OD}$ values from the active to the inactive stage $(\mathrm{p}<0.05)$.

ADCC ACTIVITY OF UC SERA AGAINST HLA-DPW9 GENE TRANSFECTED L CELLS

To investigate if these antibodies have functional roles in the pathogenesis of UC, we conducted an ADCC assay using DPw9 transfected L cells which express TM antigen on the cell surface ${ }^{6}$ as targets. As shown in fig 7 , in nine UC patients whose ADCC activity and anti-TM antibody values were simultaneously measured, a positive correlation was observed between these parameters $(r=0.932)$. All 


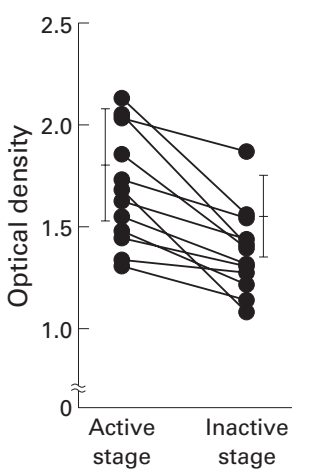

Figure 6 Changes in optical density (OD) values of sera from patients with ulcerative colitis (UC) before and after remission. When serially examined, in 11 of 12 patients with active $U C$, the $O D$ value decreased when they were in remission $(p<0.05)$.
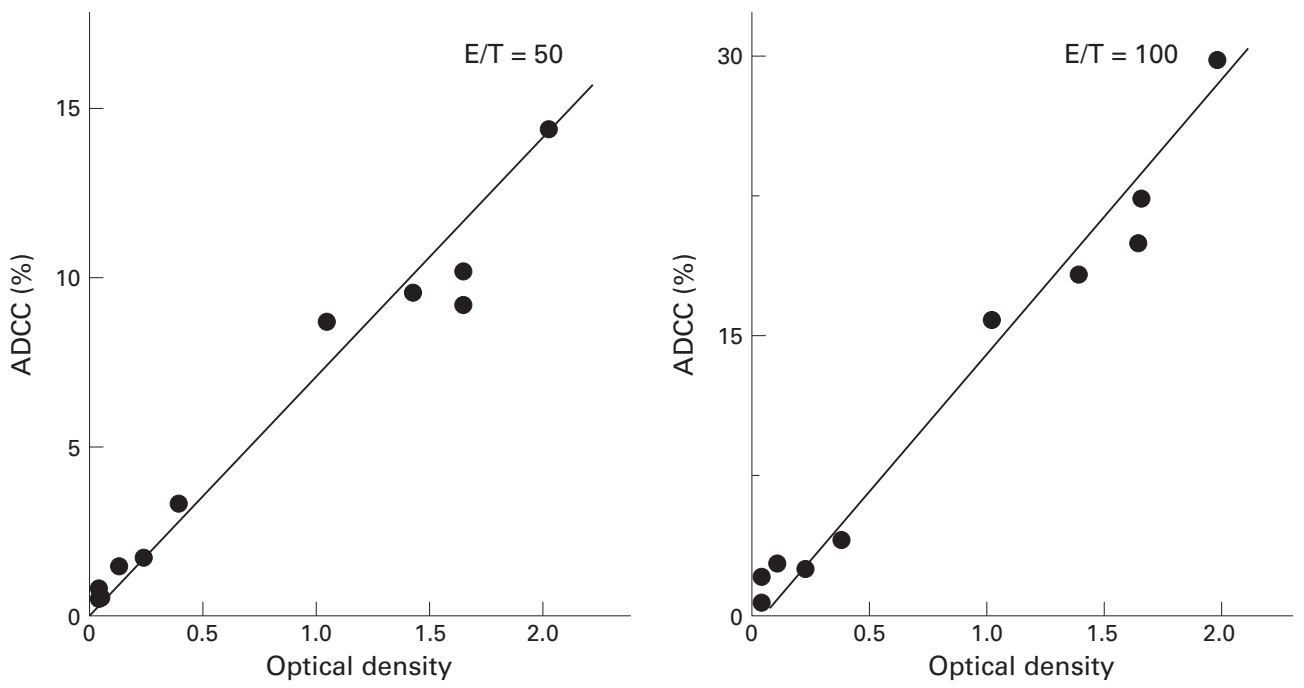

Figure 7 Correlation between antibody dependent cell mediated cytotoxicity (ADCC) activity against DPw9 transfected $L$ cells and optical density (OD) values against synthetic peptide of sera from patients with UC. All TM positive sera showed ADCC activities. A positive correlation was observed between these two parameters $(r=0.932$, effector/target $(E / T)=50 ; r=0.938, E / T=100)$.

anti-TM antibody positive UC sera showed high ADCC activity (higher than the mean +2 $\mathrm{SD}$ of normal values). Conversely, anti-TM antibody negative UC sera showed low ADCC activity (lower than the mean +2 SD of normal values; $3.3 \%$ ). L cells not transfected with DPw9 were not susceptible to ADCC.

\section{Discussion}

Allele dependent presentation of particular peptides and HLA dependent thymic shaping of the $\mathrm{T}$ cell receptor repertoire are predisposing mechanisms for susceptibility to autoimmune diseases. ${ }^{22-24}$ In UC, significant accumulation of the HLA-DR2-DPw9 haplotype was noted by serological typing of HLA molecules in Japan. ${ }^{25}$ However, there have been no further reports regarding epitopes involved in immune recognition associated with HLA in patients with UC.

TM has been identified as a putative autoantigen of UC. ${ }^{46}{ }^{27}$ If this is true, TM, which is an intracellular protein, needs to be expressed on the cell surface in association with the HLA class II molecule. It is generally accepted that the primary function of the HLA class II molecule is to present peptides derived from foreign, endocytosed proteins to $\mathrm{CD}^{+} \mathrm{T}$ cells. ${ }^{28}$ However, a recent study revealed that epitopes of endogenously synthesised protein are also expressed on the cell surface in association with HLA class II molecules. ${ }^{29}$ In this context, we have previously investigated the association of HLA class II molecules with TM peptides, and revealed that the tryptic peptide of TM indeed bound to HLA-DPw9 expressing $\mathrm{L}$ cells but not to HLA-DR2 or DQ6 expressing L cells. ${ }^{6}$ We also found that the prevalence of the DPB $1^{\star} 0901$ allele (HLADPw9) in UC used in the current study was as high as $60.4 \%$.

As mentioned previously, the amino acid sequence HIAEDADRK was chosen as it fulfilled certain primary requirements, but we selected this sequence for additional reasons: (i) it represents $66.7 \%$ homology with both the binding epitope of $\operatorname{IgE}$ from patients with shrimp allergy against shrimp TM and the antigenic epitope of $O$ volvulus TM, recognised by IgG from patients with onchocerciasis ${ }^{152}$; (ii) it is commonly found in many species; and (iii) this epitope was detected in the colonic p40 related TM that was found to be a putative autoantigen in UC. ${ }^{24}$

The strategy we used is usually employed for identification of the epitope of peptide recognised by $\mathrm{T}$ cell receptor. There are at least two reports showing that epitopes thought to be recognised by $\mathrm{T}$ cell receptors only, can in fact be recognised by antibodies also. Rafnar and colleagues $^{30}$ reported that the $\mathrm{T}$ cell epitope (Ambt 5) of ragweed allergen was recognised by IgG antibody. Extrapolating from their findings, it is possible that our peptide, which binds to HLA-DPw9, is recognised by an antibody in UC sera.

A similar but slightly different modality was presented by Senyk and colleagues ${ }^{31}$ who showed that glucagon contains both the antigenic determinant for serum antibody and the epitope peptide for $\mathrm{T}$ cell receptor side by side, and that the $\mathrm{B}$ cell epitope near the $\mathrm{T}$ cell epitope can be recognised by an antibody. This is an alternative possibility which we find less likely than the former because ADCC was observed when DPw9 transfected L cells treated with the synthetic peptide were used as target cells.

The specificity of the ELISA for the peptide was proved in two ways. Firstly, the ELISA specifically detected antibodies in immune rabbit serum but not in preimmune rabbit serum. Secondly, the antibody titre in positive sera decreased after preincubation with the synthetic peptide but not with the unrelated shuffled synthetic peptide. The clinical validity of this ELISA for the diagnosis of UC was apparent as high levels of the antipeptide antibody were detected only in UC and PSC but not in normal subjects or in patients with CD or PBC. Furthermore, in UC, levels decreased as the disease state became inactive. It may be 
particularly noteworthy that the levels of antibodies in PSC were as high as those in active UC because both diseases are often associated with each other, and HLA class II expression is commonly found in colon and bile duct epithelium in these diseases. ${ }^{32}{ }^{33}$ Some OD values in healthy volunteers may represent the presence of low titre antibody in normal individuals as reported in other autoimmune diseases. ${ }^{34}$

Despite the usefulness of ELISA in differential diagnosis and monitoring, some limitations in its sensitivity have been observed; almost $30 \%$ of active UC patients showed normal levels of the antibody. This indicates that the epitope recognised by this antibody may not be the only antigen involved in immune recognition in UC. Further elucidation of antigens other than this peptide and its application for combined assay with the present ELISA may be needed to increase the sensitivity.

Another point of special interest is the positive correlation between the anti-TM peptide antibody titre and ADCC activity, which suggests that the antibody we detected in this assay has a pathogenic role in UC.

Recently, Jenkins et al reported that TM antibodies play an important role in resistance against microfilariae in patients with onchocerciasis through an ADCC mechanism. ${ }^{21}$ They identified the B cell epitope of $O$ volvulus TM which shows $66.7 \%$ homology with the synthetic TM peptide we used for the ELISA. They also revealed that the dominant isotype of the antibody induced by vaccination was IgG1. These data support the idea that the antibody against the TM peptide detected in UC sera may cause tissue destruction through an ADCC mechanism. However, this does not necessarily rule out the possibility that other immunological responses, including $\mathrm{T}$ cell mediated effects related to the TM epitope(s), may also be involved in the pathogenesis of UC.

In this study, we revealed that a specific epitope of TM was capable of a humoral immune response in patients with UC and PSC. This may provide important biochemical information to explain the autoimmune mechanism in UC and PSC. From the experiments described here, this peptide based ELISA could provide a valuable tool for detecting TM antibody in sera because of its reproducibility and specificity. Measurements of the levels of TM antibody may help to understand disease activity and also to identify the pathognomonic character of UC.

The authors wish to thank Dr Takachika Azuma for helpful discussion and Kevin Litton for editorial assistance. This work was supported in part by grant-in-aid for scientific research from the Ministry of Education, Science and Culture of Japan.

1 Broberger O, Perlmann P. Autoantibodies in human ulcerative colitis. $\mathcal{F}$ Exp Med 1959;110:657-73.

2 Das KM, Dubin R, Nagai T. Isolation and characterization of colonic tissue-bound antibodies from patients with idiopathic ulcerative colitis. Proc Natl Acad Sci USA 1978;74: pathic ulcera
3 Takahashi F, Das KM. Isolation and characterization of a colonic autoantigen specifically recognized by colon tissuebound Ig G from idiopathic ulcerative colitis. $\mathcal{F}$ Clin Invest 1985;76:311-18.

4 Das KM, Dasgupta A, Mandal A, et al. Autoimmunity to cytoskeletal protein tropomyosin. F Immunol 1993;150: 2487-93.

5 Lees-Miller JP, Helfman DM. The molecular basis for tropomyosin isoform diversity. Bioassays 1991;13:429-37.

6 Sakamaki S, Hayashi S, Takayanagi N, et al. Autoantibodies in sera of patients with UC recognize tropomyosin peptide associated with HLA-DPw9. Gastroenterology 1996;110: A1007.

7 Meyer CG, May J, Schnittger L. HLA-DP part of concert. Immunol Today 1997;17:12.

8 Morson BC. Pathology of ulcerative colitis. Proc R Soc Med 1971;64:976-7.

9 Kirsner JB. Historical aspects of inflammatory bowel disease. $\mathcal{F}$ Clin Gastroenterol 1988;10:286-91.

10 Kaplan MM. Primary biliary cirrhosis. N Engl f Med 1987; 316:521-9.

11 Chapman RW, Arborgh BA, Rhodes JM, et al. Primary sclerosing cholangitis-a review of its clinical features, cholangiography and hepatic histology. Gut 1980;21:870-7.

12 Harvey RF, Bradshaw JM. A simple index of Crohn's disease activity. Lancet 1980;2:514.

13 Matts SG. The value of rectal biopsy in the diagnosis of ulcerative colitis. $Q \mathcal{F M}$ 1962;30:393-9.

14 Dohiman JG, Lupas A, Carson M. Long charge-rich alphahelices in systemic autoantigens. Biochem Biophys Res Commun 1993;195:686-96.

15 Shanti KN, Martin BM, Nagpal S, et al. Identification of tropomyosin as the major shrimp allergen and characterization of its IgE-binding epitopes. F Immunol 1993;10:535453.

16 Fassina G, Cassani G. Design and recognition properties of a hydropathically complementary peptide to human interleukin 1. Biochem F 1992;282:773-9.

7 Greene BM, Taylor HR, Aikawa M. Cellular killing of microfilariae of Onchocerca volvulus: eosinophil and neutrophil-mediated immune serum-dependent destruction. F Immunol 1981;127:1611-18.

18 Austin P, Trowsdale J, Rudd C, et al. Functional expression of HLA-DP genes transfected into mouse fibroblasts. Nature 1985;313:361-4.

19 Kimura A, Sasazuki T. Eleventh International Histocompatibility Workshop: Protocol for the HLA DNA typing technique. In:Tsuji K, Aizawa M, Sasazuki T, eds. New York and In:Tsuj1 K, Aizawa M, Sasazuki T, eds. New York and Oxford: HLA 1991, Proceedings of the Eleventh International Histocompatibi

20 Forcione DG, Sands B, Isselbacher KJ, et al. An increased risk of Crohn's disease in individuals who inherit the HLA class II DRB 3*0301 allele. Proc Natl Acad Sci USA 1996;93:5094-8.

21 Jenkins RE, Taylor MJ, Gilvary NJ, et al. Tropomyosin implicated in host protective responses to microfilariae in onchocerciasis. Proc Natl Acad Sci USA 1998;95:7550-5.

22 Campbell RD, Milner CM. MHC genes in autoimmunity. Curr Opin Immunol 1993;5:887-93.

23 Moller E, Bohme J, Valugerdi MA, et al. Speculations on mechanisms of HLA associations with autoimmune diseases and the specificity of autoreactive T lymphocytes. Immunol Rev 1993;118:5-19.

24 Nepom GT, Erlich H. MHC class II molecules and autoimmunity. Anпu Rev Immunol 1991;9:493-525.

25 Asakura H, Tsuchiya M, Aiso S, et al. Association of human lymphocyte-DR2 antigens with Japanese ulcerative colitis. Gastroenterology 1982;82:413-18.

26 Geng X, Biancone L, Dai HH, et al. Tropomyosin isoforms in intestinal mucosa: production of autoantibodies to tropomyosin isoforms in ulcerative colitis. Gastroenterology 1998;114:912-22.

27 Biancone L, Monteleone G, Marasco R, et al. Autoimmunity to tropomyosin isoforms in ulcerative colitis (UC) patients and unaffected relatives. Clin Exp Immunol 1998;113:198-205.

28 Brodsky FM, Guagliardi LE. The cell biology of antigen processing and presentation. Anпu Rev Immunol 1991;9: processing

29 Bodmer H, Viville S, Benoist C, et al. Diversity of endogenous epitopes bound to MHC class II molecules limited by invariant chain. Science 1994;263:1284-6.

30 Rafnar T, Brummet ME, Bassolino-Klimas D, et al. Analysis of the three-dimensional antigenic structure of giant ragweed allergen, Amb t 5. Mol Immunol 1998;35:459-67.

31 Senyk G, Nitecki D, Goodman JW. Immunogenicity of glucagon: Determinants responsible for antibody binding and lymphocyte stimulation. Science 1971;171:407-8.

32 Chapman R. Hepatobiliary disease. In: Allan RN, Rhodes JM, Hanauer SB, Keighley MRB, Alexander-Williams J, Fazio VW, eds. Inflammatory bowel disease, 3rd Edn. New York: Churchill Livingstone, 1997:637-46.

33 Chapman RW, Kelly PMA, Heryet A, et al. Expression of HLA-DR antigens on bile-duct epithelium in primary sclerosing cholangitis. Gut 1988;21:870-7.

34 Ottenhoff THM. Selective modulation of T-cell responses in autoimmunity and cancer. Immunol Today 1996;17:54-5. 